Hamilton, J. K. (1962), J. Obstet. Gynaec, Brit. Cwlth, 69, 58 Hertig, A. T (1950). Progress in Gynecology, edited by $\mathrm{J}$. V. Meigs and S. H. Sturgis, 2, 372. Grune and Stratton, New York.

Hertz, R., Bergenstal, D. M., Lipsett, M. B., Price, E. B., and Hilbish, T. F. (1958). J. Amer. med. Ass., 168, 845.

Hilbish, T. F., and Schulz, E. (1960). Amer. J. Roentgenol., 83, 66.

Hitschmann, F. (1901). Zbl. Gynäk., 28, 820.

(1928). Biologie und Pathologie des Weibes, Halban-Seitz, 7. 459 .

Holland, J. F. (1958). Amer. J. Obstet. Gynec., 75, 195.

Hreshchyshyn, M. M., Graham, J. B., and Holland, J. F. (1961). Ibid., 81, 688.

Hunter, J. S., and Dockerty, M. B. (1955). Obstet. and Gynec., 5, 598

Jones, G. S. (1954). The Management of Endocrine Disorders of Menstruation and Fertility, p. 140. Thomas, Springfield.

Kinnunen, O. (1952). Ann. Chir. Gynaec. Fenn., 41, 5.

Kullander, S. (1948). Lancet. 1, 944.

Lepage, F., Klein, M., and Schramm, B. (1953). Bull. Féd. Soc. Gynéc. Obstét. franc., 5, 36.

Levi, L. M., and Haig, P. V. (1951). Radiology, 56, 73.

Li, M. C., Hertz, R., and Bergenstal, D. M. (1958). New Engl. J. Med., 259, 66.

$(\overline{N . Y .}), 93,361$.

Spencer, D. B., Hertz, R., and Lubs, H. A. (1957). Proc. Amer. Ass. Cancer Res., 2, 226. Luft, R., Olivecrona, H., Ikkos, D., Nilsson, L.-B., and

Maier, H. C., and Taylor, H. (1947). Amer. J. Obstet. Gynec., $53,674$.

Manly, G. A. (1961). J. Obstet. Gynaec. Brit. Cwlth, 68, 277

Mathieu, A. (1939). Amer. J. Obstet. Gynec., 37, 654.

Meyer, R. (1931). Zbl. Gynäk., 55, 491.

Mohler, R. W., and McConneli, E. L. (1952). Amer. J. Obstet. Gynec.. 63, 428.

Peel, J., Dawson, J., and Mather, G. (1955). J. Obstet. Gynaec. Brit. Emp., 62. 232.

Peightal, T. C." (1934). Amer. J. Obstet. Gynec., 28, 435

Perlson, S. G., and Whitsitt, R. E. (1960). Obstet. and Gynec., 15. 175 .

Perrauit, M., Vignalou, J., and Etienne, R. (1949). Bull. Soc. méd. Hôp. Paris, 65, 1008

méd., K9, 1348., Solignac, H., and Cathala, P. (1951). Presse

Richter, W. E. (1939). Zbl. Gynäk., 63, 1567.

Schmauch, G. (1907). Surg. Gynec. Obstet., 5, 259.

Schuster, A. (1952). Arch. Gynäk., 181, 477.

Smalbraak, J. (1957). Trophoblastic Growths, p. 182. Elsevier, Amsterdam.

Smiley, I., and Clements, A. B. (1940). Amer. J. Obstet. Gynec., 40, 471 .

Smith, J. T., and Werthessen, N. T. (1941). Ibid., 41, 153.

Teacher, J. H. (1903). J. Obstet. Gynaec. Brit. Emp., 4, 145.

Wilson, K. M. (1939). Amer. J. Obstet. Gynec., 38, 824

Wirtz, L. (1951). Bull. Féd. Soc. Gynéc. Obstét. franç., 3, 797.

\title{
TREATMENT OF CHORIONEPITHELIOMA WITH METHOTREXATE
}

\section{DONALD P. C. CHAN, M.B., F.R.C.S.Ed., F.R.F.P.S., M.R.C.O.G.}

Lecturer in Obstetrics and Gynaecology, Hong Kong University

Methotrexate (4-amino-N-10-methylpteroylglutamic acid) is an antimetabolite which interferes with the participation of folinic acid (the active principle of folic acid) in nucleic acid synthesis. As the conversion of folic acid to folinic acid is an essential step in the synthesis of nucleic acid, methotrexate, which is an antagonist to folic acid, disrupts the mitotic process. Since malignant cells proliferate rapidly and constantly, thus requiring exceptionally high nucleic acid synthesis and turnover rates, the therapeutic possibilities of artificially induced folic-acid deficiency in malignant processes become apparent. Moreover, it has been shown experimentally in the rat that the tissues of the female genital tract and the foetus have a high requirement for folic acid (Hertz and Tullner, 1949; Nelson and Evans, 1949). The clinical phenomenon of macrocytic anaemia of pregnancy, responding as it does to folic-acid therapy, also appears to reflect an especially high requirement for folic acid in the rapidly growing maternal and foetal tissues of pregnant women. It has therefore been postulated that chorionepithelioma and related trophoblastic tumours originating in the foetal chorion and initially involving the uterus might prove responsive to treatment with folic-acid antagonists ( $\mathrm{Li}$ et al., 1956 ; Hertz et al., 1958).

Treatment of chorionepithelioma and related trophoblastic tumours with methotrexate, with gratifying results in most instances, has been reported in recent years (Li et al., 1956, 1957, 1958; Holland 1958; Hertz et al., 1958; Bagshawe and Brooks, 1959 ; Buckle, 1959, 1961; Perlson and Whitsitt, 1960; Bagshawe and McDonald. 1960 ; Manly, 1961; Hreshchyshyn et al., 1961 : Hamilton, 1962). It is difficult to state the exact number of cases so treated, as some of them may well have been reported on more than one occasion.

Most of the cases of chorionepithelioma in Hong Kong are treated in the Gynaecological Department, University of Hong Kong. From January 1, 1960, to
June 30, 1961, seven cases of chorionepithelioma were treated with methotrexate with very satisfactory results.

\section{Case 1}

A gravida-4 aged 28 was admitted to hospital on January 18,1960 , with a history of seven months' vaginal bleeding following three months' amenorrhoea for which a dilatation and curettage (D. \& C.) was done in another hospital one month previously. The uterus was enlarged to the size of a 12-weeks pregnancy and a bluish nodule $5 \mathrm{~mm}$. in diameter was present in the anterior lip of the cervix. The male frog test of the urine was positive up to a dilution of 1 in 200 and radiography of the chest showed several small round opacities scattered over both lungs.

Total hysterectomy, bilateral salpingo-oophorectomy, and right internal iliac artery ligation were done on January 22 , after which she developed a productive cough with bloodstreaked sputum. On February 16 a bluish nodule about $2.5 \mathrm{~cm}$. in diameter appeared in the anterior vaginal wall $2.5 \mathrm{~cm}$. above the introitus. Another bluish nodule $1.25 \mathrm{~cm}$. in diameter was found in the vestibule just below the external urethral meatus three days later. In the meantime an $x$-ray film of the chest taken on February 5 (Fig. 1) revealed progressively more extensive involvement of both lungs, and the male frog test, which was negative four days after operation, became positive up to a dilution of 1 in 10 . It was decided to treat her with methotrexate, and this was started on February 19. but was discontinued after $50 \mathrm{mg}$. had been given because of diarrhoea and the presence of blood in the stool. She was found to have amoebiasis, which was treated with emetine and emetine bismuth iodide. Methotrexate was started again a week later. Five subsequent courses of $100 \mathrm{mg}$. each were given at intervals of two to three weeks. The vaginal and vulval metastases disappeared completely and the male frog test became and remained negative 5 and 10 weeks respectively after beginning methotrexate therapy, and soon afterwards there were hardly any pulmonary metastases in the chest $x$-ray film (Fig. 2). The notable side-effects were stomatitis, diarrhoea, and alopecia.

After completion of the fifth course her general condition was excellent and she was discharged on May 22 apparently 
cured. She did not return and could not be traced. It is bolieved that, being the wife of a fisherman, she was drowned in a typhoon which broke out soon after her discharge.

\section{Case 2}

A gravida-6 aged 32 was admitted on February 2, 1960 , with a history of continuous bleeding per vaginam for three months. Her last pregnancy ended in a full-time delivery two years previously. On admission her general condition was good and her uterus became enlarged to the size of a 16-weeks pregnancy. The male frog test was positive and the chest $x$-ray picture was normal. Total hysterectomy and bilateral salpingo-oophorectomy were performed on February 9. a week after admission. Radiography of the chest a week after operation revealed the presence of

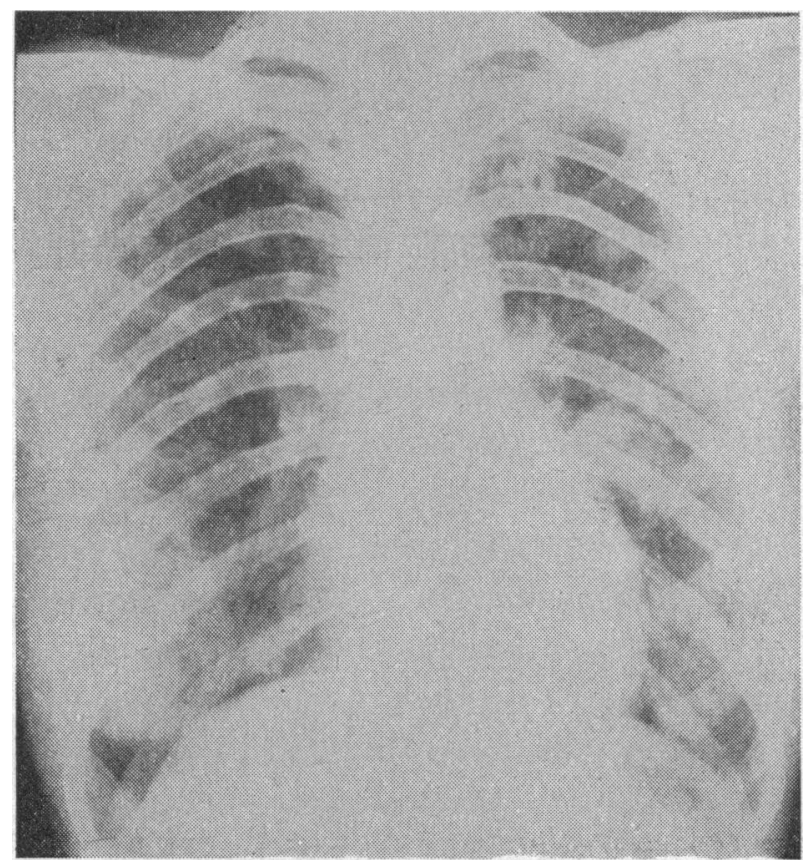

Fig. 1.-Case 1. Radiograph taken on February 5, 1960, before treatment with methotrexate.

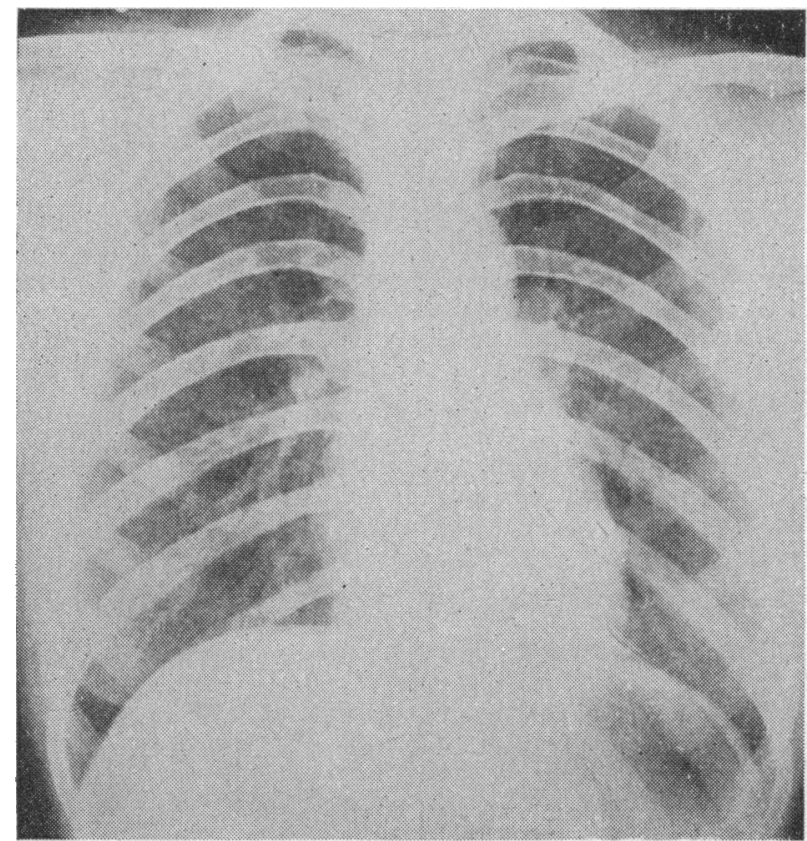

Fig. 2.-Case 1. Radiograph taken on April 28, 1960, after three courses of methotrexate. pulmonary metastases, which became progressively more extensive. The male frog test was positive in 1 in 5 dilution on March 17, six weeks after admission.

Methotrexate therapy was begun on March 19. five weeks after operation. She had a severe sore throat and stomatitis on the third day of methotrexate therapy and a generalized skin rash on the fourth. The drug was, however, not discontinued until $100 \mathrm{mg}$. had been given. The stomatitis became worse and reached its maximal intensity on the third day after the drug had been stopped. The second course of $55 \mathrm{mg}$. was given when the oral lesion had been cleared for a week. Another three courses of 70-75 mg. each were given at fortnightly intervals. stomatitis appearing on the last day of each course. The male frog test became negative three weeks after the commencement of the first course of methotrexate and remained so throughout. The pulmonary shadows gradually disappeared till, after the completion of the fifth or last course, they were barely visible.

Two years and three months after her first admission she was examined and found to be well.

\section{Case 3}

A gravida-7 aged 41 was admitted on April 18, 1960, in a very poor condition. Eighteen months before admission she had had a hydatidiform mole evacuated by abdominal hysterotomy in another hospital. Two months later she had pain on the right side of the chest, dyspnnea. and cough with blood-streaked sputum. During the same period she had occasional bleeding per vaginam, the amount never being profuse. Since then she had been treated with antituberculous chemotherapy (streptomycin, para-aminosalicylic acid. and isoniazid hydrazide). The chest pain had disappeared for a year but returned, the cough persisted, but the vaginal bleeding had stopped for two months before her admission. On admission pelvic examination revealed nothing abnormal. The male frog test was positive up to a dilution of 1 in 200 and radiological examination of the chest showed multiple round opacities in both lung fields.

Five courses of methotrexate of $100 \mathrm{mg}$. each were given at fortnightly intervals. Total hysterectomy and bilateral salpingo-oophorectomy were carried out between the secnnd and third courses. Macroscopic and microscopical examination of the specimen. however. failed to reveal the presence of a primary growth in the uterus. Stomatitis appeared on the last day of each of the first four courses, but marked ulceration of both lips and gums occurred after the fifth. The male frog test became negative and the pulmonary opacities almost completely disappeared after the fifth course.

She was not seen for seven weeks after completion of the fifth course, and was readmitted on August 18 with marked dyspnoea and repeated attacks of haemoptysis. The male frog test was posituve up to a dilution of $1: 10$ and radiography of the chest again revealed multiple opacities. Despite two further courses of methotrexate $175 \mathrm{mg}$. and $90 \mathrm{mg}$. respectively), her condition deteriorated, the male frog test became and remained positive up to a dilution of 1 in 100 and the chest $x$-ray film showed an increase in size and number of metastases in the lungs. She died on October 21, six months after the commencement of methotrexate therapy. Post-mortem examination revealed multiple secondaries in the lungs, liver, and right occipital lobe of the brain.

\section{Case 4}

A gravida-2 aged 25 was admitted on July 25,1960 . with a history of continuous bleeding per vaginam since the delivery of a stillbırth two and a half months previnusly; the bleeding was profuse on two occasions. after each of which a D. \& C. was done. Histological examination of the curettings of the second D. \& C. revealed chorionepi- 
theliomatous tissue. On examination the uterus was found to be enlarged to the size of a 12-weeks pregnancy. The male frog test was positive up to a dilution of 1 in 400 and chest $x$-ray examination showed multiple roundish opacities. Total hysterectomy and right salpingo-oophorectomy were done on August 2, a week after admission.

Methotrexate was started a week after the operation. Altogether five courses of $100 \mathrm{mg}$. each were given at intervals of two to three weeks. Stomatitis, skin rash, diarrhoea, and alopecia made their appearance during and after the first two courses. Stomatitis was the only bad side-effect seen in the subsequent three courses. The male frog test became and remained negative three months after methotrexate was first given. The secondaries in the lungs increased in size and number for five weeks after beginning methotrexate therapy but gradually disappeared until they were barely visible.

On examination 22 months after her first admission she was found to be perfectly well.

\section{Case 5}

A gravida-3 aged 26 was admitted on September 12, 1960. She had been delivered of a stillbirth seven and a half weeks previously and since then had had continuous vaginal bleeding, which became profuse three weeks before admission. D. \& C. had been done and chorionepitheliomatous tissue obtained nine days before her transference from another hospital. Examination on admission revealed that the uterus was enlarged to the size of a 14-weeks pregnancy. The male frog test was positive up to a dilution of 1 in 10 and $x$-ray examination of the chest showed metastatic lesions in the lungs. Total hysterectomy was performed on September 16, four days after admission.

The male frog test remained positive and the pulmonary shadows became more extensive. Methotrexate was started four weeks after admission. Only two courses of $100 \mathrm{mg}$. each were given at a fortnight's interval. The male frog test became and remained negative and the chest radiography showed great improvement. She did not return for the third course of methotrexate, and since then has not been traced.

\section{Case 6}

A gravida- $7+2$ aged 46 had a 3 -months abortion nine months previously. She was admitted to another hospital, where a D. \& C. was done. A month later she started to have bleeding per vaginam on and off which was sometimes very profuse and for which two further curettings had been done four and a half and three months previously. Total hysterectomy and bilateral salpingo-oophorectomy were carried out one month before admission. As she had pain on the right side of the chest for a week and dyspnoe for a day, she was transferred to the University Gynaecological Unit on June 1, 1961. The male frog test was positive up to a dilution of 1 in 400 and $x$-ray examination of the chest revealed multiple roundish opacities in both lung fields.

She was given seven courses of methotrexate of $100 \mathrm{mg}$. each at fortnightly intervals. She developed a generalized skin rash on the last day of her first course, and both rash and stomatitis on the last day of her second and third courses. After the completion of the second course, the male frog test became and remained negative and the pulmonary secondaries completely disappeared after the seventh course. On examination one year after her first admission she was found to be well.

\section{Case 7}

A gravida-3+3 aged 37 had had a hydatidiform mole evacuated by abdominal hysterotomy five years previously. Since then she had had one abortion and one full-term spontaneous delivery four and a half and three and a half years previously. She was first seen on April 6, 1961, with a history of having had vaginal bleeding for five days after six weeks' amenorrhoea. Radiography of the chest was clear and the male frog test positive up to $1: 10$. The uterus was enlarged to the size of an 8-weeks pregnancy. she was treated as a case of threatened abortion. On June 14 , two months after she was first seen when she complained of having had blood-streaked sputum for 10 days, $x$-ray examination of the chest showed multiple opacities. On vaginal examination two bluish nodules $(1 \mathrm{~cm}$. and $5 \mathrm{~mm}$. in diameter respectively) were found in the vestibule just below the external urethral meatus and the uterus was enlarged to the size of a 12-weeks pregnancy.

She was admitted, and total hysterectomy and left salpingo-oophorectomy were performed on June 16. Since the fourth post-operative day 11 courses of methotrexate of $100 \mathrm{mg}$. each were given. She developed generalized skin rash on the third day of the first course and alopecia and vomiting during all the subsequent courses. The pulmonary opacities increased in size and number during her first two weeks in hospital, gradually decreased over the next four weeks, remained stationary for two weeks, and thereafter again increased in size and number. The vulval metastases disappeared five weeks after the starting of methotrexate therapy, but reappeared three weeks later. The male frog test continued to be positive up to a dilution of $1: 10$. Her condition deteriorated gradually, and she committed suicide on April 14, 1962, 10 months after the beginning of methotrexate therapy.

\section{Discussion \\ Surgical Treatment}

Removal of the uterus was done in all the seven cases, six of these after admission, in order (1) to prevent further metastases, (2) to prevent haemorrhages from the uterine lesion which could be continuous and profuse, and (3) to afford confirmation of the diagnosis. Even though no primary growth was found in one case (Case 3), massive neoplastic and extensively infiltrative lesions were found in the other five. The pelvis was found to be very vascular with multiple congested and thinwalled venous plexuses in all the cases, including Case 3 in which no primary lesion was found. Continuous oozing in Case 1 could be controlled only after ligation of the internal iliac artery. Though total hysterectomy and bilateral salpingo-oophorectomy were performed in four cases (including the one done elsewhere), it is thought unnecessary to remove the appendages as chorionepithelioma metastasizes by blood-stream.

\section{Methotrexate Therapy}

With the exception of Case 6, where the uterus was removed before admission, and Case 3, where two courses of methotrexate had been given before the surgical intervention and where no primary was found in the uterus, the pulmonary metastases increased in size and number (or, in Case 2, made their appearance) after hysterectomy. This seems to suggest that manipulation causes further spread of the disease. Therefore, in the absence of profuse vaginal bleeding, methotrexate should be given before surgical extirpation of the uterus if a reasonably certain diagnosis is made.

The optimal dose for a Chinese woman of average weight (100 lb. (45 kg.) or less) seems to be $100 \mathrm{mg}$. per course ( $5 \mathrm{mg}$. four times a day for five days), as toxic symptoms usually make their appearance on the last day of the course. The dosage cannot be calculated on the basis of body weight alone, as shown by the first two cases. Case 1 (weight $100 \mathrm{lb}$. $(45 \mathrm{~kg}$.) ) had mild and transient stomatitis only on the last day of each course (100 mg.). Case 2 (weight $130 \mathrm{lb}$. (59 kg.)) was given 
$100 \mathrm{mg}$. in the first course, but stomatitis and generalized skin rash appeared on the third day (after only $50 \mathrm{mg}$. had been given) and became so severe that the patient was rendered miserable for more than a week. It was later found that the optimal dose for this patient was $70 \mathrm{mg}$. per course. One must not therefore aim at giving a full predetermined or calculated dose.

The following scheme is being used. Methotrexate $5 \mathrm{mg}$. is given four times a day orally after blood, renal function, and liver function have been assessed until toxic symptoms (discussed at greater length later) appear or when $100 \mathrm{mg}$. has been given (toxic symptoms, if present, do not reach their maximal intensity, or, if absent, may only make their appearance two to four days after the drug has been discontinued). If no toxic symptoms appear a week after $100 \mathrm{mg}$. has been given, a second course can be started with the same precaution. With a dosage of $5 \mathrm{mg}$. four times a day, the drug can be given until toxic symptoms appear or, without them, until $120 \mathrm{mg}$. is given. During treatment the patient should be under close observation, which includes a daily complete physical examination, complete blood examination, chemical and microscopical examination of urine, fluid intake and output record, examination of stool and sputum for occult blood, and a weekly $x$-ray examination of the chest, male frog test, liver-function test, and blood-urea examination, and, consequently, she should be in hospital during the first and all subsequent courses, while she may be discharged to return home during the intervals.

The interval between courses should not be too long. The drug should be restarted 7 to 10 days after the previous one if no toxic symptoms occur. Otherwise it should be given after all toxic symptoms and signs have disappeared for a week. The average interval is usually two weeks. It is difficult to say if the deterioration of the condition and eventual death of the patient (Case 3) can be ascribed to the long interval-namely, seven and a half weeks-between the fifth and sixth courses. The patient responded very well to methotrexate at the end of the fifth course. After a lapse of seven and a half weeks without any drug therapy her condition deteriorated rapidly despite two further courses of methotrexate, to which the neoplasm must have become resistant.

The number of courses should not be fixed. Methotrexate should be given till the male frog test becomes persistently negative, pulmonary opacities as shown by $x$-ray examination of the chest have completely disappeared, and secondaries elsewhere in the bodyfor example, vagina, vulva, skin, gum-completely resolved. The discontinuation of the drug before full clinical "cure" is fraught with the danger of the neoplasm becoming resistant to the drug as illustrated in Case 3. Eleven courses had been given to Case 7 , five courses each to Cases 1,2 , and 4 , seven courses each to Cases 3 and 6, and two courses to Case 5 (who did not return after the second course).

\section{Toxic Manifestations}

Malaise, weakness, and anorexia are common complaints during and especially towards the end of every course of methotrexate therapy. They should not be considered as indications for drug withdrawal since they invariably disappear after each course.

Stomatitis is the commonest toxic manifestation of any significance. It usually appears towards the end of each course and reaches its maximal intensity two to four days after the drug is discontinued, when it gradually disappears. The incidence and severity of stomatitis are related to the dental condition. The dentist should be consulted, carious teeth extracted, and the mouth carefully washed after meals.

Diarrhoea with or without vomiting occasionally occurs, usually towards the end of the second course.

Daily white-cell and differential count, platelet count, and haemoglobin determination should be carried out. Severe leucopenia, thrombocytopenia, and anaemia necessitating drug suspension were not encountered in the present series. Susceptibility to infection, which, however, was not associated with leucopenia, occurred in Case 1 (where apical abscess of a tooth made its appearance and amoebiasis of the colon flared up during drug therapy) and in Case 4 (where staphylococcal infection of the eye, upper lips, and then thumb followed one another in quick succession after completion of treatment). As there is no significant reduction in the number of circulating phagocytes, the phenomenon can perhaps be explained by an inhibition of the phagocytic function of leucocytes by the antifolic agent (Tanakadate and Saruhashi, 1952).

A generalized erythematous skin rash made its appearance during the first course of methotrexate in four patients (Cases 2, 4, 6, and 7), but did not appear in the subsequent courses in three of these four. In the remaining case it appeared towards the end of each course.

Alopecia was encountered in every patient except Case 5, where only $200 \mathrm{mg}$. of methotrexate had been given. Regrowth of the hair invariably occurred within one month after completion of drug therapy.

\section{Results}

The general condition of the patients greatly improved. Though appetite was invariably lost during therapy, it was soon restored after the completion of each course. Every patient put on weight.

The male frog test, which was positive in every case and up to a dilution of 1 in 200 or higher in four cases, became and remained negative in all except Cases 3 and 7. In Case 3 the male frog test did become negative, but it became positive again and remained so until the patient died. In Case 7 it was persistently positive. In three cases (Nos. 2, 5, and 6), the male frog test became negative two to three weeks after starting methotrexate therapy, when only 100 to $200 \mathrm{mg}$. had been given. In three other cases (Nos. 1, 3, and 4) it did not become negative until 10 to 13 weeks after the drug therapy, when $350 \mathrm{mg}$., $500 \mathrm{mg}$., and $400 \mathrm{mg}$. respectively had been given.

Pulmonary metastases, as shown by serial $x$-ray films, underwent marked regression in all cases. In Cases 3 and 7 the initial favourable response was followed by an increase in number and size of pulmonary secondaries. This present study confirms the statement made by Hilbish and Schulz (1960) that changes in the radiological findings, particularly those of the lungs, correlate very well with changes in clinical status and laboratory findings in patients undergoing chemotherapy. Secondaries in the vagina and/or vulva found in Cases 1 and 7 resolved completely five weeks after commencing methotrexate therapy, when $150 \mathrm{mg}$. and $300 \mathrm{mg}$. had been given respectively, but they reappeared 
and increased in size in Case 7 despite further courses of methotrexate.

\section{Summary}

The rationale of methotrexate therapy is discussed and a short review of the literature given.

From January 1, 1960, to June 30, 1961, seven cases of chorionepithelioma were treated with methotrexate in the Gynaecological Department, University of Hong Kong. Summaries of the seven case records are given.

While hysterectomy, which was performed in all the seven cases, is thought to be necessary in the treatment of chorionepithelioma, the increase in size and number of pulmonary metastases in five of the seven cases seems to suggest that manipulation causes further spread of the disease. In the absence of profuse vaginal bleeding, therefore, methotrexate should be given before surgical extirpation of the uterus if a reasonably certain diagnosis is made. The optimal dose for a Chinese woman of average weight seems to be $100 \mathrm{mg}$. per course $(5 \mathrm{mg}$. four times a day for five days). The dosage cannot, however, be calculated on the basis of body weight alone. The scheme used is described. The interval between courses is found to be two weeks in most instances. The number of courses should not be fixed, and methotrexate should be given until the male frog test becomes persistently negative, pulmonary opacities completely disappear, and secondaries elsewhere in the body completely resolve. While stomatitis is the commonest toxic manifestation of any significance, diarrhoea, generalized erythematous skin rash, and alopecia are also encountered.

Two patients (Cases 3 and 7) are dead, after having been treated with methotrexate for 6 and 10 months respectively. Two patients (Cases 1 and 5) have been lost trace of three months and one month respectively after the commencement of methotrexate therapy. Both of them were showing marked improvement when they were last seen. Three patients (Cases 2, 4, and 6) remain well with no sign of disease whatsoever 27,22 , and 12 months respectively after their first admissions.

I thank Professor Daphne W. C. Chun for her advice and for permission to compile the report. and Miss Gladys $\mathrm{H}$. Dodds for encouragement and valuable criticism.

REFERENCES

Bagshawe, K. D., and Brooks, W. D. W. (1959). Lancet, 1, 653 - and McDonald, J. M. (1960). Brit. med. J., 2, 426.

Buckle, A. E. R. (1959). Ibid., 2, 1210.

- (1961). Ibid., 1, 173.

Hamilton, J. K. (1962). J. Obstet. Gynaec. Brit. Cwlth, 69, 58.

Hertz, R., Bergenstal, D. M., Lipsett, M. B., Price, E. B., and Hilbish, T. F. (1958). J. Amer. med. Ass., 168, 845. and Tullner, W. W. (1949). Endocrinology, 44, 278.

Hilbish, T. F., and Schulz, E. (1960). Amer. J. Roentgenol., 83,66 .

Holland, J. F. (1958). Amer. J. Obstet. Gynec., 75, 195.

Hreshchyshyn, M. M., Graham, J. B., and Holland, J. F. (1961). Ibid., 81688.

Li, M. C., Hertz, R., and Bergenstal, D. M. (1958). New Engl. J. Med., 259, 66 .

- and Spencer, D. B. (1956). Proc. Soc. exp. Biol. $(N . Y), 93,$.361 .

- Spencer, D. B., Hertz, R., and Lubs, H. A. (1957). Proc. Amer. Ass. Cancer Res., 2, 226.

Manly, G. A. (1961). J. Obstet. Gynaec. Brit. Cwlth, 68, 277.

Nelson, M. M., and Evans, H. M. (1949). J. Nutr., 38, 11.

Perlson, S. G., and Whitsitt, R. E. (1960). Obstet. and Gynec., 15,175

Tanakadate, Y., and Saruhashi, Y. (1952). Nagoya J. med. Sci., 15, 237.

\section{EFFECT OF METHYLDOPA IN CARCINOID DISEASE}

\author{
BY
}

\section{G. I. NICHOLSON, M.B., M.R.A.C.P.}

\author{
M. C. EVANS, B.Sc.
}

AND

\section{R. O. H. IRVINE, M.D., M.R.C.P., M.R.A.C.P. \\ Auckland Hospital, Auckland, New Zealand}

Alpha-methyldopa (alpha - methyl - 3,4 - dihydroxy - DL phenylalanine) is an effective inhibitor of aromatic amino-acid decarboxylation in man (Oates et al., 1960); as such it interferes with the synthesis of noradrenaline and serotonin.

Oates and his co-workers showed that the increased urinary excretion of 5-hydroxytryptamine (serotonin) that occurs after infusion of 5-hydroxytryptophan (5H.T.P.) in normal subjects was greatly reduced during treatment with alpha-methyldopa. Two patients with the carcinoid syndrome were then given alpha-methyldopa (Sjoerdsma et al., 1960). The excretion of the serotonin metabolite 5-hydroxyindoleacetic acid (5H.I.A.A.) decreased by $60-70 \%$, while there was a marked increase in the urinary excretion of 5-H.T.P. No significant effect on symptoms was apparent. Noble (1961) noticed subjective improvement in a man with the carcinoid syndrome who was treated with the $L$ isomer of alpha-methyldopa, but there was no reduction in 5-H.I.A.A. excretion and 5-H.T.P. was not detected in the urine. Davis et al. (1961) gave alpha-methyldopa to four patients with the carcinoid syndrome with some relief from flushing in one patient but no symptomatic relief in the other three. In all cases 5-H.I.A.A. excretion was unchanged.

We have given the more potent $\mathrm{L}$ isomer of alphamethyldopa (methyl dopa) to three patients with the carcinoid syndrome. In one there was marked clinical improvement with a decreased excretion of 5-H.I.A.A. in the urine; the second patient did not show any change ; and the third could not tolerate methyldopa.

\section{Case Histories}

Case 1.-A 66-year-old man presented with a nine-months history of abdominal pain, loss of appetite, loss of weight, and frequent loose bowel motions. For six months he had noticed that his face was redder than usual and he had been told that he had a "drinker's nose." Over the same period he noticed flushing attacks two or three times a week. Although his face became flushed with the attacks he felt cold and was noted to have cool extremities. Severe abdominal pain occurred with each attack and was followed by diarrhoea. Wheezing was prominent with the attacks but also occurred in between.

On examination his face was flushed, there was evidence of loss of weight, and his liver, which was hard and nodular, was enlarged to four fingerbreadths below the costal margin. Blood pressure was $130 / 75 \mathrm{~mm}$. $\mathrm{Hg}$. An ejection systolic murmur which could be heard at the pulmonary area was loudest during a flushing attack. He later developed the signs of tricuspid incompetence. At laparotomy widespread metastases were found in the liver and throughout the peritoneal cavity. The histological appearances were those of carcinoid tumour. The excretion of 5-H.I.A.A. was $260 \mathrm{mg} . / 24$ hours. 